\title{
Productivity and Injectivity of Horizontal Wells
}

\author{
Contract N0. DE-FG22-93BC14862 \\ Department of Petroleum Engineering \\ Stanford University \\ Stanford, CA 94305
}

Contract Date: March 10, 1993

Anticipated Completion: March 10, 1998

\author{
Principal Investigator: Khalid Aziz \\ Co-Investigator: Thomas A. Hewett \\ Research Associate: Sepehr Arbabi \\ Administrative Assistant: Marilyn Smith \\ Technical Project Manager (DOE): Thomas B. Reid
}

\section{Quarterly Report}

Reporting Period: October 1, 1996 - December 31, 1996

"U.S./DOE patent clearance is not required prior to the publication of this document" 


\section{Disclaimer}

This report was prepared as an account of work sponsored by an agency of the United States Government. Neither the United States Government nor any agency thereof, nor any of their employees, makes any warranty, express or implied, or assumes any legal liability or responsibility for the accuracy, completeness, or usefulness of any information, apparatus, product, or process disclosed, or represents that its use would not infringe privately owned rights. Reference herein to any specific commercial product, process, or service by trade name, trademark, manufacturer, or otherwise does not necessarily constitute or imply its endorsement, recommendation, or favoring by the United States Government or any agency thereof. The views and opinions of authors expressed herein do not necessarily state or reflect those of the United States Government or any agency thereof. 


\section{Summary of Technical Progress}

A number of activities have been carried out in the last three months. A list outlining these efforts is presented below.

- The fourth review meeting of the Horizontal Well Industrial Affiliates Program was held on October 10-11 at Stanford. The meeting was well attended and well received. In addition to the project presentations, a number of member presentations were also made at the meeting. Professor Aziz attended the 1996 SPE International Conference on Horizontal Well Technology in Calgary in November where he was a Keynote speaker and made a presentation on a paper done under this project.

- Draft plans for the continuation of the two-phase flow experiments were drawn up and sent to Marathon and other members for their review and comments. Series of new experiments with and without the wire wrapped screens used in 1996 are being considered for 1997.

- Work on the application of horizontal wells for producing gas condensate reservoirs was continued. After verification of the black oil formulation, emphasis is being put on the compositional case where simulation runs have been set up to check the results against a semi-analytical solution.

- The previous work on the effects of heterogeneities on horizontal well performance was continued and a paper on the subject was completed. Future work in this area will deal with a careful analysis of the interaction of heterogeneity and production performance.

- Research work on developing coarse grid methods to study cresting in horizontal wells was continued. The previous correlations for optimum grid size, breakthrough time, and post breakthrough behavior (i.e., water-oil ratio) were further tested and optimized. Procedures to derive pseudo-functions either using numerical correlations or coarse grid simulations have been proposed and successfully tested.

The Ph.D. project under the last activity listed above is nearing completion, and is the subject of this quarterly report. Here, we only present a brief account of this work. The details will be in the dissertation which will be submitted to DOE once it becomes available.

\section{Correlations for Cresting Behavior in Horizontal Wells (Tasks 1 and 4)}

Accurate representation of cresting behavior requires fine grid simulations which are costly and not always practical. In this project, simple correlations for quick estimates of breakthrough time, maximum oil rate, and post-breakthrough behavior are derived based 
on an appropriate set of dimensionless variables and an extensive number of simulation runs.

\section{Dimensionless Equations}

Correlations are more general and reliable when derived based on the fundamental flow equations, so that the important physical mechanisms are automatically incorporated in the correlations. The flow equations can be made dimensionless and dimensionless variables (DVs) controlling fluid movement can be identified. Sensitivity studies can identify the most important DVs, which can then be used in developing correlations.

The basic flow equations for oil and water can be written as:

$$
\begin{gathered}
\frac{\partial}{\partial x}\left[\frac{k_{h} k_{r_{o}}}{B_{o}} \frac{\partial \Phi_{o}}{\partial x}\right]+\frac{\partial}{\partial z}\left[\frac{k_{v} k_{r o}}{B_{o}} \frac{\partial \Phi_{o}}{\partial z}\right]-\frac{\tilde{q}_{o}}{B_{o}}=\mu_{o} \phi \frac{\partial}{\partial t}\left(\frac{S_{o}}{B_{o}}\right) \\
\frac{\partial}{\partial x}\left[\frac{k_{h} k_{r w}}{B_{w}} \frac{\partial \Phi_{w}}{\partial x}\right]+\frac{\partial}{\partial z}\left[\frac{k_{v} k_{r w}}{B_{w}} \frac{\partial \Phi_{w}}{\partial z}\right]-\frac{\tilde{q}_{w}}{B_{w}}=\mu_{w} \phi \frac{\partial}{\partial t}\left(\frac{S_{w}}{B_{w}}\right)
\end{gathered}
$$

Nomenclature contains the variable definitions. Dimensionless time is defined as:

$$
t_{D}=\frac{\Delta \rho g \lambda_{o} k_{v} t}{\phi_{e f} h_{o}}
$$

where $\Delta \rho$ is the initial density difference at the WOC at reservoir conditions, and is given by:

$$
\Delta \rho=\rho_{w}-\rho_{o}
$$

with

$$
\rho_{w}=\frac{\rho_{w s t d}}{B_{w}}
$$

and

$$
\rho_{o}=\frac{\rho_{\text {ostd }}+\rho_{g s t d} R_{s}}{B_{o}}
$$

Furthermore:

$$
\begin{gathered}
q_{D}=\frac{q_{o} B_{o}}{2 \pi \Delta \rho g \lambda_{o} \sqrt{k_{v} k_{h}} L h_{o}} \\
N_{p D}=\frac{N_{p} \sqrt{\frac{k_{v}}{k_{h}}}}{2 \pi \phi_{e f} L h_{o}{ }^{2}} \\
p_{D}=\frac{p-p_{S T D}}{\Delta \rho g h_{o}} \\
c_{l D}=c_{l} \Delta \rho g h_{o}, \quad l=o, w
\end{gathered}
$$

Normalized saturations are 


$$
\begin{aligned}
& S_{w}^{*}=\frac{S_{w}-S_{w c}}{1-S_{w c}-S_{o r}} \\
& S_{o}^{*}=\frac{S_{o}-S_{o r}}{1-S_{w c}-S_{o r}}
\end{aligned}
$$

so that

$$
S_{o}^{*}+S_{w}^{*}=1
$$

Relative permeabilities can be written as

$$
\begin{aligned}
& k_{r w}=k_{r w r o} k_{r w}{ }^{*} \\
& k_{r o}=k_{r o c w} k_{r o}{ }^{*}
\end{aligned}
$$

With normalized relative permeabilities given by power functions of saturations as

$$
\begin{gathered}
k_{r w}^{*}=\left(S_{w}^{*}\right)^{n_{w}} \\
k_{r o}^{*}=\left(S_{o}^{*}\right)^{n_{o}}
\end{gathered}
$$

Using this set of DV in Equations 1 and 2 together with a parameter $M$ defined as

$$
M=\frac{k_{\text {rwro }}}{k_{\text {rocw }}} \frac{\mu_{o}}{\mu_{w}}
$$

we obtain:

$$
\begin{gathered}
\frac{\partial}{\partial x_{D}}\left[\frac{k_{r o}^{*}}{B_{o}} \frac{\partial \Phi_{o D}}{\partial x_{D}}\right]+\frac{\partial}{\partial z_{D}}\left[\frac{k_{r o}^{*}}{B_{o}} \frac{\partial \Phi_{o D}}{\partial z_{D}}\right]-2 \pi q_{o D}=\frac{\partial}{\partial t_{D}}\left(\frac{S_{o}^{*}}{B_{o}}\right) \\
\frac{\partial}{\partial x_{D}}\left[\frac{k_{r w}^{*}}{B_{w}} \frac{\partial \Phi_{w D}}{\partial x_{D}}\right]+\frac{\partial}{\partial z_{D}}\left[\frac{k_{r o}^{*}}{B_{w}} \frac{\partial \Phi_{w D}}{\partial z_{D}}\right]-2 \pi q_{w D}=\frac{1}{M} \frac{\partial}{\partial t_{D}}\left(\frac{S_{w}^{*}}{B_{w}}\right)
\end{gathered}
$$

Where:

$$
q_{l D}=\frac{q_{D} k_{r l}^{*}}{k_{r o}^{*}+M k_{r w}^{*}}, \quad l=o, w
$$

and

$$
q_{o D}+M q_{w D}=q_{D}
$$

These dimensionless equations show the important parameters that should be used to develop correlations for water cresting behavior. The boundary conditions are no-flow on the lateral edge and on the top of the reservoir. A large aquifer to give pressure support is placed at the bottom of the reservoir. In the next section, we briefly describe the procedure used to develop the correlations and show their application to a base case. 


\begin{tabular}{|l|l|}
\hline Oil column, $h$ & $100 \mathrm{~m}$ \\
\hline Horizontal permeability, $k_{h}$ & $1 \mathrm{D}$ \\
\hline Vertical permeability, $k_{v}$ & $1 \mathrm{D}$ \\
\hline Porosity, $\phi$ & 0.1 \\
\hline Oil density, $\rho_{o}$ (standard) & $1000 \mathrm{~kg} / \mathrm{m}^{3}$ \\
\hline Water density, $\rho_{w}($ standard $)$ & $900 \mathrm{~kg} / \mathrm{m}^{3}$ \\
\hline Gas density, $\rho_{g}($ standard $)$ & $1 \mathrm{~kg} / \mathrm{m}^{3}$ \\
\hline Gas-oil solubility ratio $R s$ & 0 \\
\hline Oil viscosity, $\mu_{o}$ & $1 \mathrm{cp}$ \\
\hline Water viscosity, $\mu_{w}$ & $1 \mathrm{cp}$ \\
\hline Oil compressibility, $c_{o}$ & $1 \mathrm{e}-5 \mathrm{bar}^{-1}$ \\
\hline Water compressibility, $c_{w}$ & $1 \mathrm{e}-5 \mathrm{bar}^{-1}$ \\
\hline Rock compressibility, $c_{r}$ & 0.0 \\
\hline Conate water saturation, $S_{w c}$ & 0 \\
\hline Residual oil saturation, $S_{o r}$ & 0 \\
\hline Oil relative permeability exponent, $n_{o}$ & 1 \\
\hline Water relative permeability exponent, $n_{w}$ & 1 \\
\hline Oil relative permeability at $S_{w c}, k_{r o c w}$ & 1 \\
\hline Water relative permeability at $S_{o r}, k_{r w r o}$ & 1 \\
\hline Production rate, $q\left(q_{D}=0.1\right)$ & $5428.74 \mathrm{~m}^{3} / \mathrm{day}$ \\
\hline
\end{tabular}

Table 1: Basic data set for simulation runs

\section{Water cresting correlations}

The base case for the runs was defined for the situation when the reservoir behaves as if it is infinite, with mobility ratio equal to one. The well is at the top of the reservoir and the relative permeability curves are straight lines. Table 1 contains the data for this base case.

In developing correlations, each DV was varied over a large range of practical situations, as shown in Table 2. For example, the dimensionless rate varies from 0.01 to 1.0, which corresponds to a variation in the rate from $500 \mathrm{~m}^{3} /$ day to $50000 \mathrm{~m}^{3} /$ day.

Figure 1 shows an example of the grid used to make the runs. The horizontal producer is represented by the point close to the top of the reservoir, drilled in the orthogonal direction $\mathrm{y}$ of the plane $\mathrm{xz}$. The horizontal injector crosses the entire reservoir in the $\mathrm{x}$ direction and is located at the bottom of the aquifer.

The next sections describe the specific procedures used to obtain the correlations. It can be roughly estimated that it took 5000 runs with the commercial simulator ECLIPSE to obtain the results of this work. Time of each run varied from 1 minute to 4 hours of CPU, with a total time of around $3000 \mathrm{CPU}$ hours. 


\begin{tabular}{|c|c|c|}
\hline PARAMETER & BASE CASE & VARIATION \\
\hline$q_{D}$ & 0.1 & 0.01 to 1 \\
\hline $\mathrm{M}$ & 1 & 0.1 to 100 \\
\hline$x_{e D}$ & 20 & 2.5 to 20 \\
\hline$h_{w D}$ & 1 & 0.2 to 1 \\
\hline$n_{o}$ & 1 & 1 to 5 \\
\hline$n_{w}$ & 1 & 1 to 3 \\
\hline
\end{tabular}

Table 2: Base data for the simulations and range of variation of each DV.

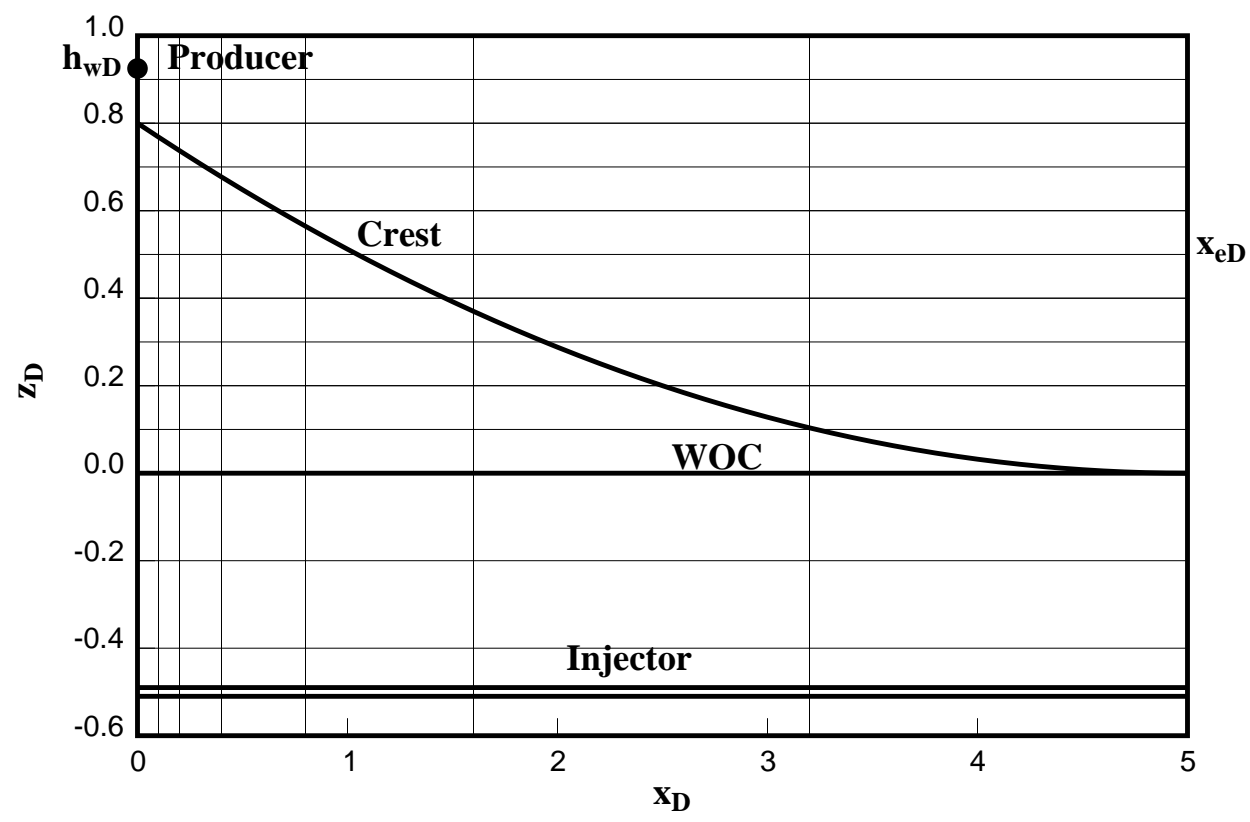

Figure 1: Grid example for the simulations.

\section{Breakthrough time}

The correlations for $t_{b t D}$ were derived using the following Equation:

$$
\ln \frac{t_{b t D}^{0}}{t_{b t D}}=\alpha \Delta z_{D}
$$

which indicates that $\ln t_{b t D}$ is a linear function of $\Delta z_{D}$, with $t_{b t D}^{0}$ and $\alpha$ being the parameters to be found.

The procedure used was to record the values of BT for each run, assumed as the time for a water-cut equal to 0.001 . Then, a linear regression with the six points (see Figure 2) of $\Delta z_{D}$ and $t_{b t D}$ was performed, using Equation 23. These regressions gave maximum errors of $0.5 \%$. Figure 2 shows one example of such matches for $q_{D}=0.5$.

With this procedure, for each DV, the values of $t_{b t D}^{0}$ and $\alpha$ were obtained. The variations in DVs were made from the base case, that is, only one DV was varied for each 


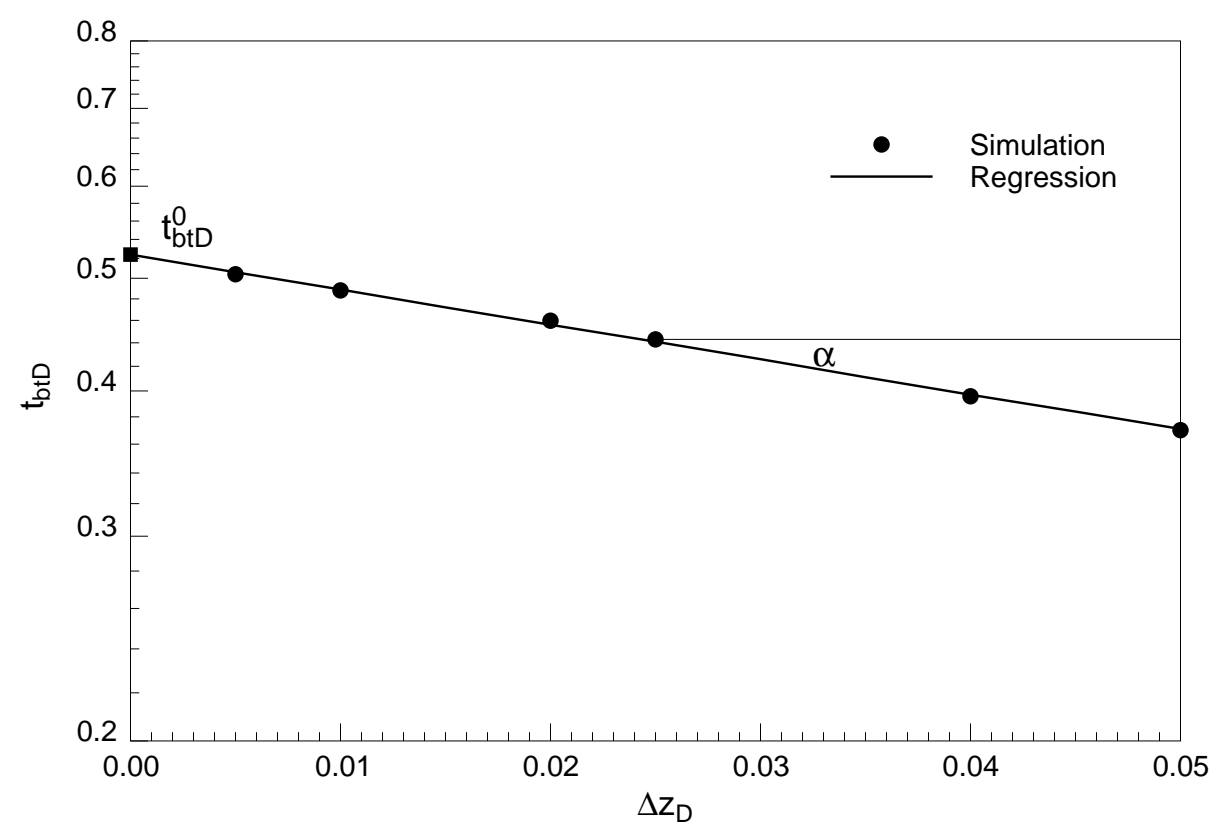

Figure 2: Match of $t_{b t D}$ vs $\Delta z_{D}$ for $q_{D}=0.5$

set of $\Delta z_{D}$. It was assumed that each DV could be matched independently, so that the final correlation could be a combination of several functions of just one variable. This assumption implies that simultaneous variations in two or more DVs can be calculated as a combination of results from separate variations in each DV from the base case. The simulation runs showed this to be a good assumption for most combinations of DVs, except for simultaneous variations of $q_{D}$ with $\mathrm{M}$ or $x_{e D}$. For this reason, an extra set of runs varying these DVs was made.

A combination of linear regression and the polytope procedure [1] was used for obtaining final correlations. Since more than one function could normally match the points, the criteria used to select the best function for each match was a maximum error of $5 \%$ in the simplest possible function. All the functions could finally be categorized in two main groups:

1. Polynomial functions:

$$
f(y)=A+B f(x)+C f(x)^{2}+D f(x)^{3}
$$

with $f(x)=x$ or $\ln (x)$ and $f(y)=y$ or $\ln (y)$.

2. Extensions of the linearized functions:

$$
f(y)=A(B f(x)+C)^{D}+E
$$

with $f(x)=x^{a}$ or $\ln (x+a)$ or $e^{a x^{b}}$. 
The parameters $t_{b t d}^{0}$ and $\alpha$ can be written as:

$$
t_{b t D}^{0}=f t\left(q_{D}\right) f t(M) f t\left(x_{e D}\right) f t\left(h_{w D}\right) f t\left(n_{o}\right) f t\left(n_{w}\right) f t\left(q_{D}, M\right) f t\left(q_{D}, x_{e D}\right)
$$

and

$$
\alpha=f a\left(q_{D}\right) f a\left(h_{w D}\right) f a\left(n_{o}\right) f a\left(n_{w}\right) f a\left(q_{D}, M\right)
$$

where the functions are given by one of Equations 24 and 25 . The values of each constant and the exact equation for each function are given in Table 3.

The extra correction factors to account for simultaneous variation of $q_{D}$ with $X_{e D}$ or $\mathrm{M}$ are given by:

$$
\begin{gathered}
f t\left(q_{D}, M\right)=a f t(M)+b f t(M) \ln \left(q_{D}\right) \\
f t\left(q_{D}, x_{e D}\right)=\operatorname{aft}\left(q_{D}\right)+b f t\left(q_{D}\right) \ln \left(x_{e D}\right) \\
f a\left(q_{D}, M\right)=a f a(M)+b f a(M) q_{D}
\end{gathered}
$$

where the coefficients are also shown in Table 3.

As an example of use of Table 3, consider correlation functions for $f t\left(q_{D}\right)$ and $f a\left(q_{D}\right)$. For $f t\left(q_{D}\right)$, Equation 25 is used with $x=q_{D}$ giving $f(x)=x^{a}=q_{D}{ }^{a}$ and $y=f t\left(q_{D}\right)$, resulting in

$$
f t\left(q_{D}\right)=A\left(B q_{D}^{a}+C\right)^{D}+E
$$

while for $f a\left(q_{D}\right)$, Equation 24 and Table 3 suggest $f\left(q_{D}\right)=\ln q_{D}$ and $f(y)=\ln f a\left(q_{D}\right)$, yielding

$$
\ln \left(f a\left(q_{D}\right)\right)=A+B \ln \left(q_{D}\right)+C\left(\ln \left(q_{D}\right)\right)^{2}+D\left(\ln \left(q_{D}\right)\right)^{3}
$$

with the regression parameters listed in the Table.

\section{Post-breakthrough behavior}

The correlations for post-breakthrough behavior (PBB) were derived using the following equation for oil-production:

$$
q_{o D}=q_{D}\left(\frac{t_{b t D}}{2 t_{D}-t_{b t D}}\right)^{m}
$$

where $\mathrm{m}$ is the parameter to be calculated by a non-linear regression with the DVs and is equal to 0.5 for the VE assumption used by Tiefenthal [2].

The water-cut $f_{w}$ is given by:

$$
f_{w}=1-\frac{q_{o D}}{q_{D}}
$$

and the WOR at standard conditions by:

$$
W O R=\frac{B_{o}}{B_{w}} \frac{q_{D}}{q_{o D}}-1
$$




\begin{tabular}{|c|c|c|c|c|c|c|c|c|c|c|}
\hline Function & Equation & $\mathrm{f}(\mathrm{x})$ & $\mathrm{f}(\mathrm{y})$ & $\mathrm{a}$ & $\mathrm{b}$ & $\mathrm{A}$ & $\mathrm{B}$ & $\mathrm{C}$ & $\mathrm{D}$ & $\mathrm{E}$ \\
\hline$f t\left(q_{D}\right)$ & 25 & $x^{a}$ & $\mathrm{y}$ & -0.73603 & - & 0.93757 & 0.22567 & 0.49051 & 2.88443 & -0.09768 \\
\hline$f t(M)$ & 25 & $e^{a x^{b}}$ & $\mathrm{y}$ & -0.18211 & -0.94590 & 1.0 & -2.19823 & 2.83255 & 1.0 & 0.0 \\
\hline$f t\left(x_{e}\right)$ & 25 & $\ln (x+a)$ & $\mathrm{y}$ & 0.00023 & - & 1.0 & 0.51495 & -0.45280 & 0.05202 & 0.0 \\
\hline$f t\left(h_{w D}\right)$ & 25 & $e^{a x^{b}}$ & $\mathrm{y}$ & -2.27532 & 2.64935 & 1.0 & -1.08884 & 1.11303 & 1.0 & 0.0 \\
\hline$f t\left(n_{o}\right)$ & 25 & $e^{a x^{b}}$ & $\mathrm{y}$ & -0.04474 & 1.45274 & 1.0 & 1.05029 & 0.0 & 1.0 & 0.0 \\
\hline$a f t m(M)$ & 25 & $x^{a}$ & $\mathrm{y}$ & 7.8999 & - & 0.96084 & 2.13949 & 0.05343 & -0.06452 & 0.08278 \\
\hline$b f t m(M)$ & 25 & $x^{a}$ & $\mathrm{y}$ & -1.23410 & - & 1.0 & 0.88026 & 0.04590 & 0.13461 & -1.0 \\
\hline$a f t x\left(q_{D}\right)$ & 24 & $\ln \mathrm{x}$ & $\mathrm{y}$ & - & - & 1.13148 & -0.05918 & -0.02191 & 0.01276 & - \\
\hline$b f t x\left(q_{D}\right)$ & 24 & $\ln \mathrm{x}$ & $\mathrm{y}$ & - & - & -0.03318 & 0.05135 & 0.02453 & -0.00194 & - \\
\hline$f a\left(q_{D}\right)$ & 24 & $\ln \mathrm{x}$ & $\ln \mathrm{y}$ & - & - & 2.44506 & 0.74312 & 0.08108 & -0.01379 & - \\
\hline$f a\left(h_{w D}\right)$ & 25 & $x^{a}$ & $\mathrm{y}$ & -5.16519 & - & 0.95795 & 0.92981 & 0.34618 & 0.05673 & 0.0 \\
\hline$f a\left(n_{o}\right)$ & 25 & $x^{a}$ & $\mathrm{y}$ & 0.43174 & - & 1.0 & 1.00177 & 0.0 & 1.0 & 0.0 \\
\hline$f a\left(n_{w}\right)$ & 25 & $x^{a}$ & $\mathrm{y}$ & 1.0 & - & 1.0 & 0.33433 & 0.66566 & -2.73097 & 0.0 \\
\hline$a f a m(M)$ & 25 & $x^{a}$ & $\mathrm{y}$ & -0.16534 & - & 1.0 & 0.96120 & 0.0 & 1.0 & 0.0 \\
\hline$b f a m(M)$ & 24 & $\ln \mathrm{x}$ & $\mathrm{y}$ & - & - & 0.18891 & 1.61377 & 0.0 & 0.0 & - \\
\hline$f m\left(q_{D}\right)$ & 24 & $\ln \mathrm{x}$ & $\ln \mathrm{y}$ & - & - & -0.83732 & -0.13767 & -0.04924 & -0.01046 & - \\
\hline$f m(M)$ & 25 & $\ln (x+a)$ & $\mathrm{y}$ & 1.18780 & - & 1.0 & 3.0 & -1.21430 & 0.08580 & 0.0 \\
\hline$f m\left(x_{e}\right)$ & 25 & $x^{a}$ & $\mathrm{y}$ & -1.89472 & - & 1.0 & 2.73268 & 0.98855 & 1.51177 & 0.0 \\
\hline$f m\left(h_{w D}\right)$ & 24 & $x$ & $\mathrm{y}$ & - & - & 0.22840 & 0.7787 & 0.0 & 0.0 & 0.0 \\
\hline$f m\left(n_{o}\right)$ & 25 & $e^{a x^{b}}$ & $\mathrm{y}$ & -0.04130 & 1.0 & 1.0 & 1.03490 & 0.0 & 1.0 & 0.0 \\
\hline$a f m x\left(q_{D}\right)$ & 24 & $\ln \mathrm{x}$ & $\ln \mathrm{y}$ & - & - & -0.35914 & 0.21539 & 0.17615 & 0.00654 & - \\
\hline$b f m x\left(q_{D}\right)$ & 24 & $\ln \mathrm{x}$ & $\mathrm{y}$ & - & - & 1.18917 & 0.13644 & 0.09088 & 0.02874 & - \\
\hline
\end{tabular}

Table 3: Values of the constants for the correlations of $t_{b t D}^{0}, \alpha$ and $m\left(q_{o D}\right)$.

A procedure similar to that used to obtain the correlations for the parameters of BT was used for the parameter m. Again the same functions described by Equations 24 and 25 can be applied. Dimensionless rates are still matched using their original values and the other parameters are added as correction factors. An extra correction factor to account for simultaneous variations of $q_{D}$ and $x_{e D}$ was also added.

Figure 3 shows the comparison of $q_{o D}$ vs $t_{D}$ calculated by the above correlations for $\mathrm{BT}$ and $\mathrm{PBB}$ with the simulation performed for the base case. The plot of $f_{w}$ is in Figure 4 and WOR in Figure 5. Except for a small deviation near breakthrough, a very good match is obtained.

\section{Cumulative oil recovery}

The dimensionless cumulative oil recovery is given by the area below the curve in Fig. 3 . Numerically, it can be written for a given $t_{D}$ as:

$$
N_{p D}=q_{D} t_{b t D}+\int_{t_{b t D}}^{t_{D}} q_{o D}(\tau) d \tau
$$

where the first term indicates $N_{p t b t D}$, that is, $N_{p}$ up to BT and the second term indicates $N_{p}$ for PBB. Using Equation 33 and integrating, $N_{p D}$ can be written as:

$$
N_{p D}=\frac{1-2 m}{2-2 m} N_{p t b t D}+\frac{1}{2-2 m}\left[q_{o D}\left(t_{D}\right)\left(2 t_{D}-t b t D\right)\right]
$$

The plot of $N_{p D}$ vs $t_{D}$ for the base case obtained from both simulation and correlation is shown in Figure 6 where an excellent match is obtained. 


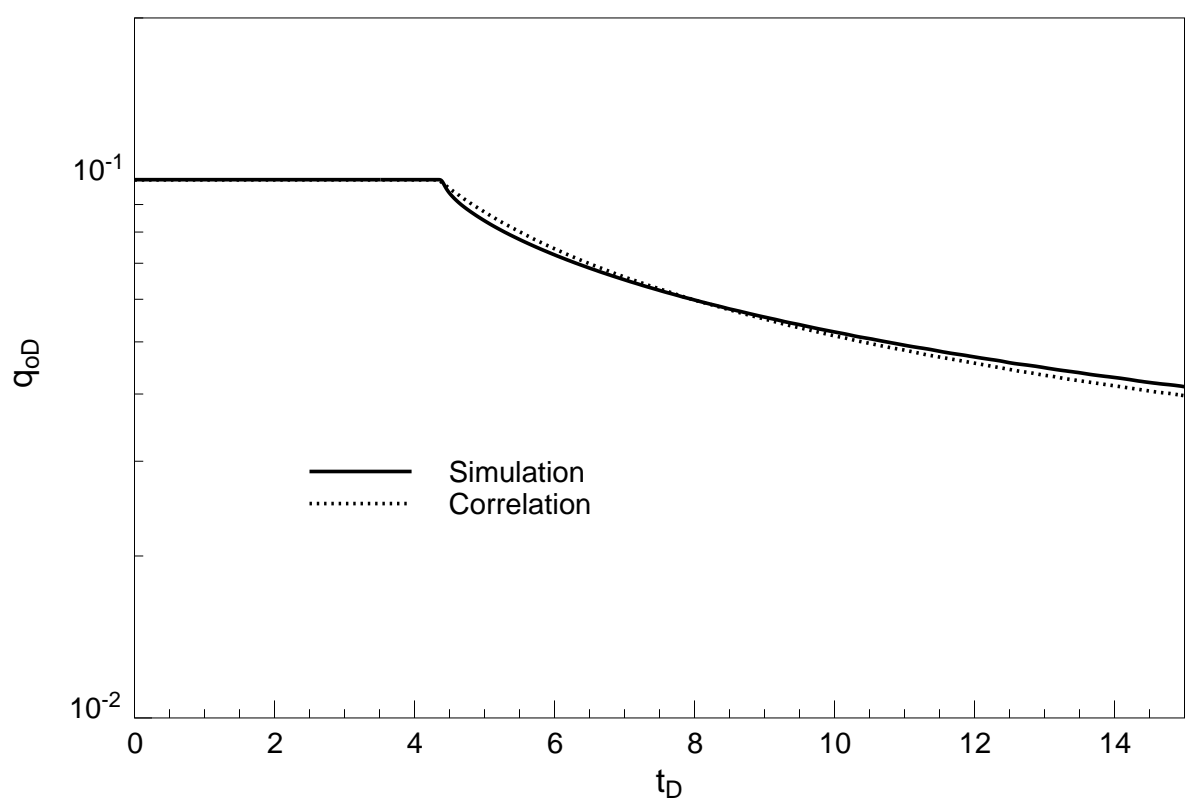

Figure 3: Comparison of BT and $q_{o D}$ correlations with simulation results for the base case.

\section{Recovery factor}

The recovery factor $(\mathrm{RF})$ is given by:

$$
R F=\frac{N_{p}}{N_{o}}
$$

where $N_{p}$ is the cumulative oil recovery and $N_{o}$ is the recoverable oil in place, which is given by:

$$
N_{o}=X W h_{o} \phi_{e f}
$$

A plot of RF vs $t_{D}$ for the base case is given in Figure 7.

\section{Conclusions}

The results reported here and other calculations show that the correlations developed in this work can be applied to a wide range of conditions for predicting the water breakthrough time (BT) and the water-oil-ratio (PBB) for horizontal wells.

All of the correlations are based on the assumption of two-phase, two-dimensional flow in homogeneous reservoirs. 


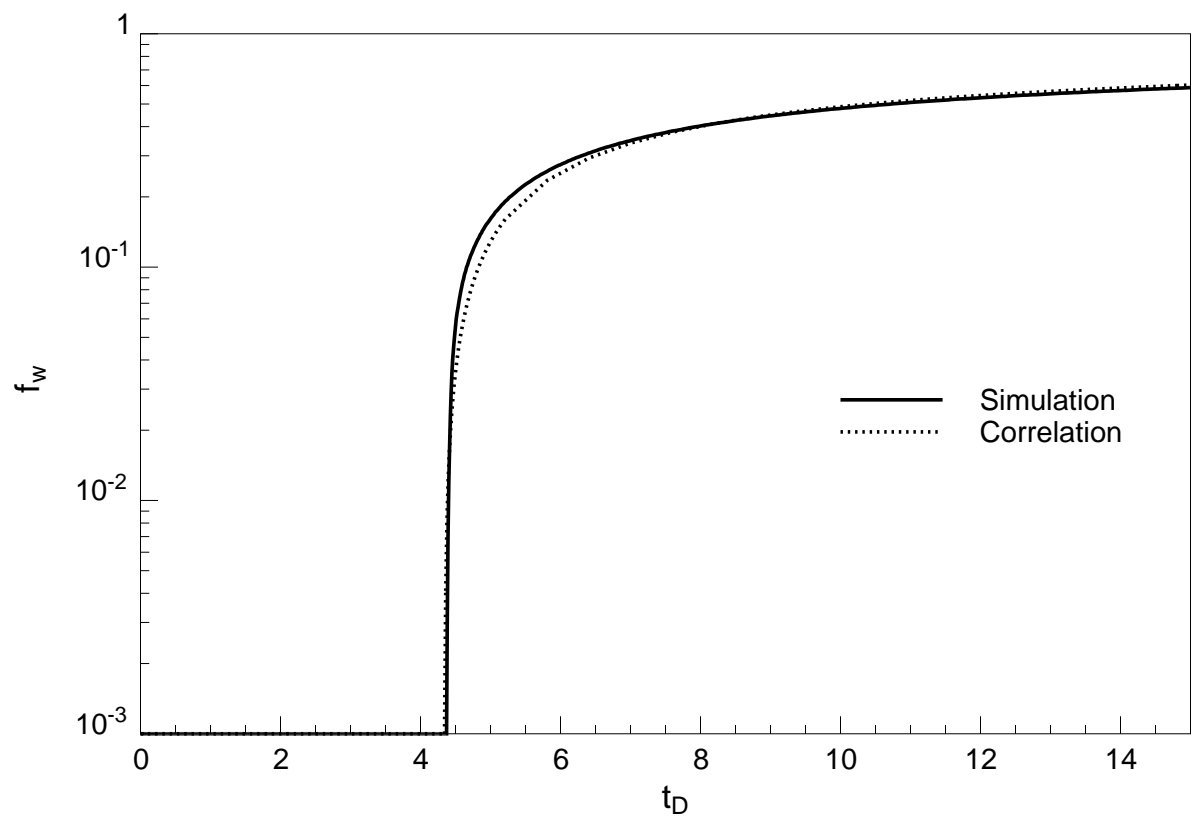

Figure 4: Comparison of BT and $f_{w}$ correlations with simulation results for the base case.

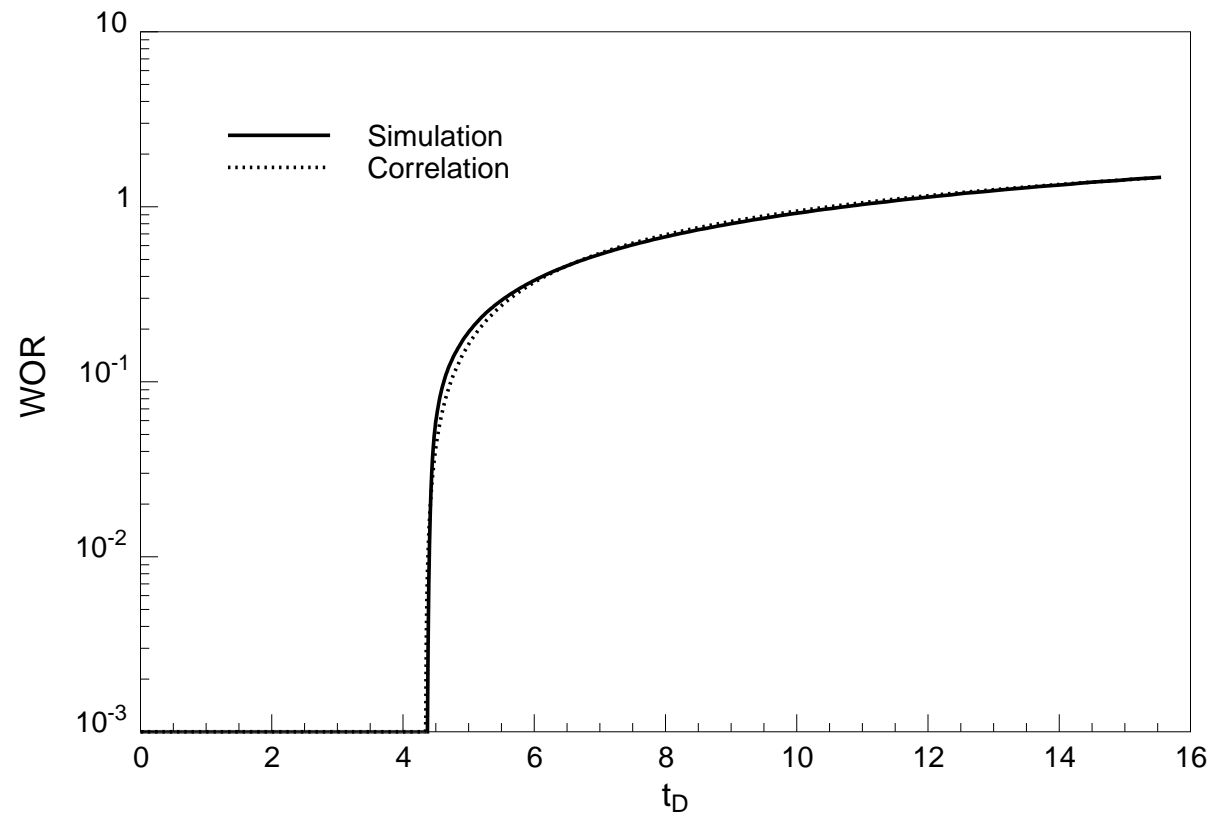

Figure 5: Comparison of BT and WOR correlations with simulation results for the base case. 


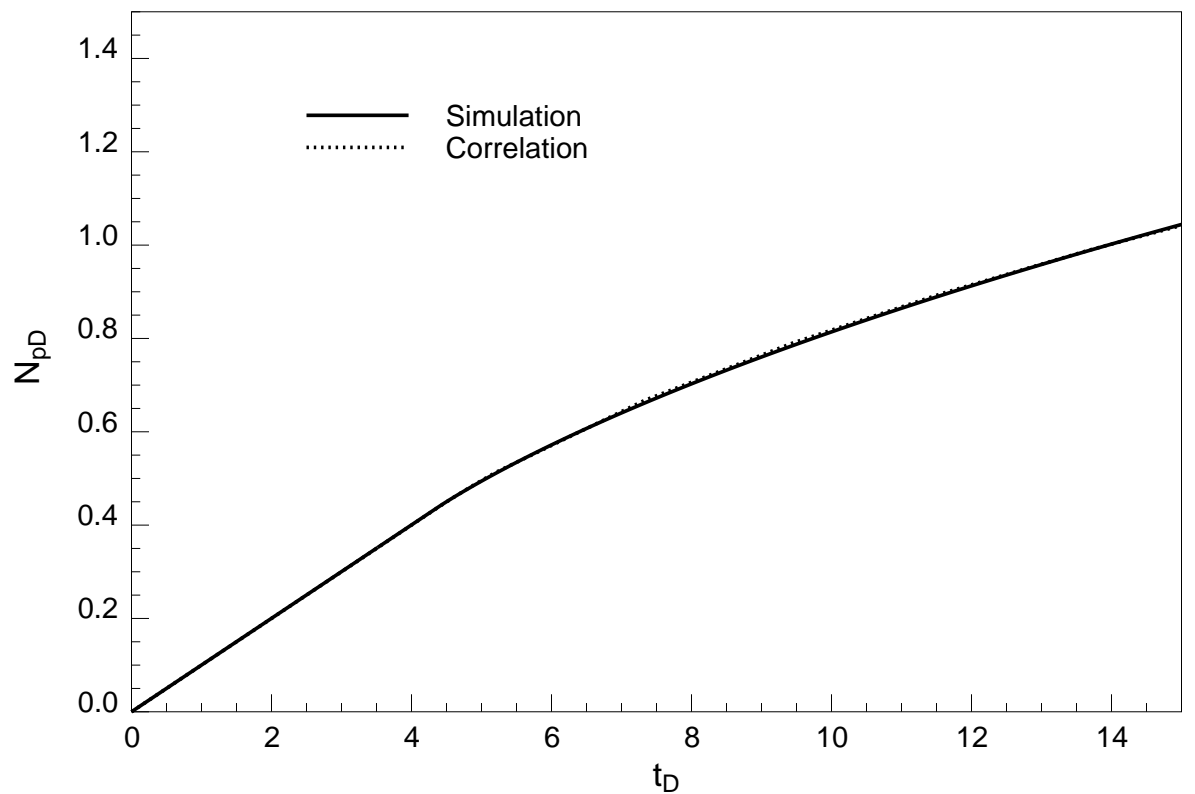

Figure 6: Comparison of $N_{p}$ vs $t_{D}$ between the correlations and the simulation results for the base case.

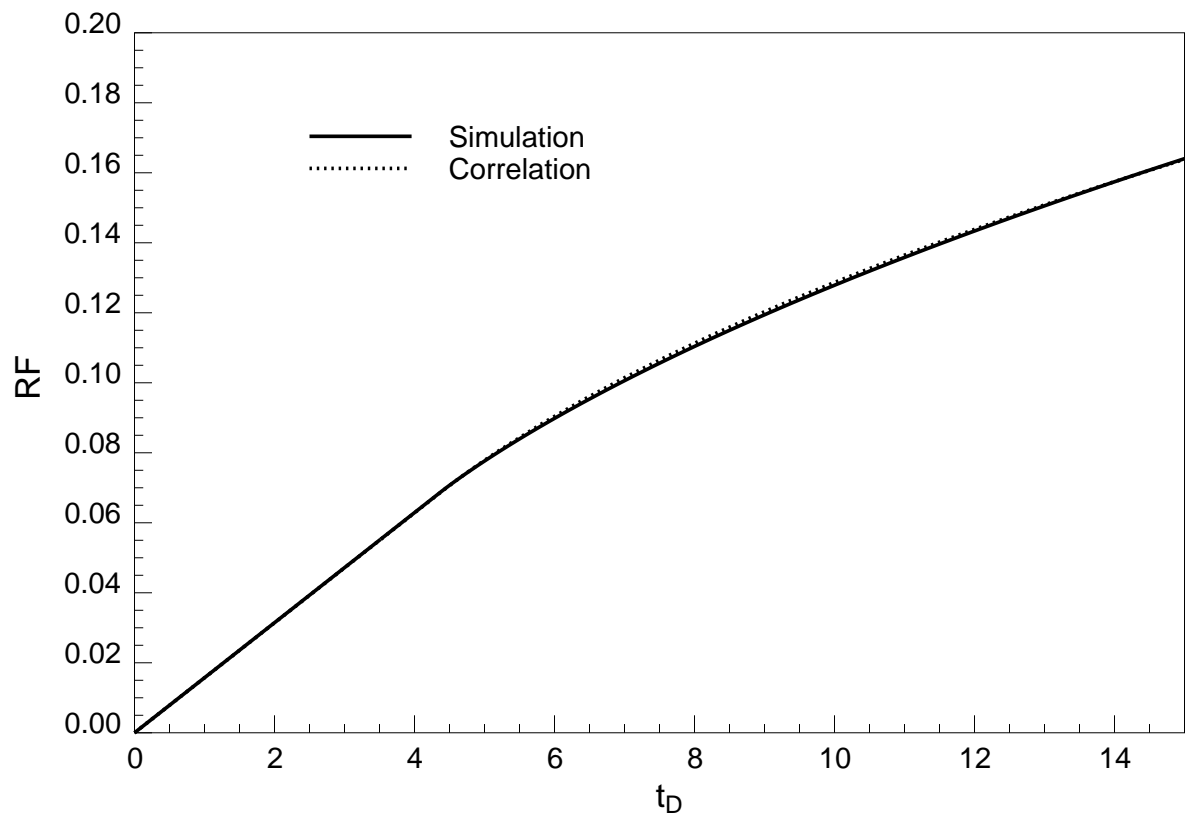

Figure 7: Comparison of RF vs $t_{D}$ between the correlations and the simulation results for the base case. 


\section{NOMENCLATURE}

$B$ - formation volume factor , $\mathrm{m}^{3} / \mathrm{m}^{3}$

$B T$ - breakthrough time

$c$ - compressibility, $P a^{-1}$

$D$ - depth, distance from the surface, $m$

$D V$ - dimensionless variables

$f_{w}$ - fractional water flow (water-cut).

$F V F$ - formation volume factor , $\mathrm{m}^{3} / \mathrm{m}^{3}$

$g$ - gravity acceleration $=9.81 \mathrm{~m} / \mathrm{s}^{2}$

$G O C$ - gas-oil contact

$G O R$ - gas-oil ratio

$h$ - height, distance from the bottom of the reservoir, $m$

$H W$ - horizontal well

$k$ - permeability , $m^{2}$

$l$ - phase

$L$ - well length, $m$

$P B B$ - Post-breakthrough behavior

$p$ - pressure, $P a$

$q$ - rate at reservoir conditions, $\mathrm{m}^{3} / \mathrm{s}$

$Q$ - rate at standard conditions, $\mathrm{m}^{3} / \mathrm{s}$

$R s$ - solubility ratio, $\mathrm{m}^{3} / \mathrm{m}^{3}$

$R F$ - Recovery Factor.

$r$ - radial direction, $m$

$S$ - saturation

$t$ - time, $s$

$V$ - volume, $m^{3}$

$V E$ - vertical equilibrium

$V W$ - vertical well

$x$ - main horizontal direction, with the origin in the well, $m$; or arbitrary variable

$w$ - width (y direction), $m^{3}$

$W O C$ - water-oil contact

$W O R$ - water-oil rate.

$W C T$ - water-cut.

$y$ - horizontal y direction, $m$; or arbitrary variable

$z$ - vertical direction, with the origin at the top of the reservoir, $m$

Greek :

$\gamma=$ hydrostatic gradient $=\rho g, P a / m$

$\mu=$ viscosity $P$ a.s

$\rho=$ density, $\mathrm{kg} / \mathrm{m}^{3}$

$\phi=$ porosity

$\Phi=$ potential, $P a$

$\theta=$ angle 


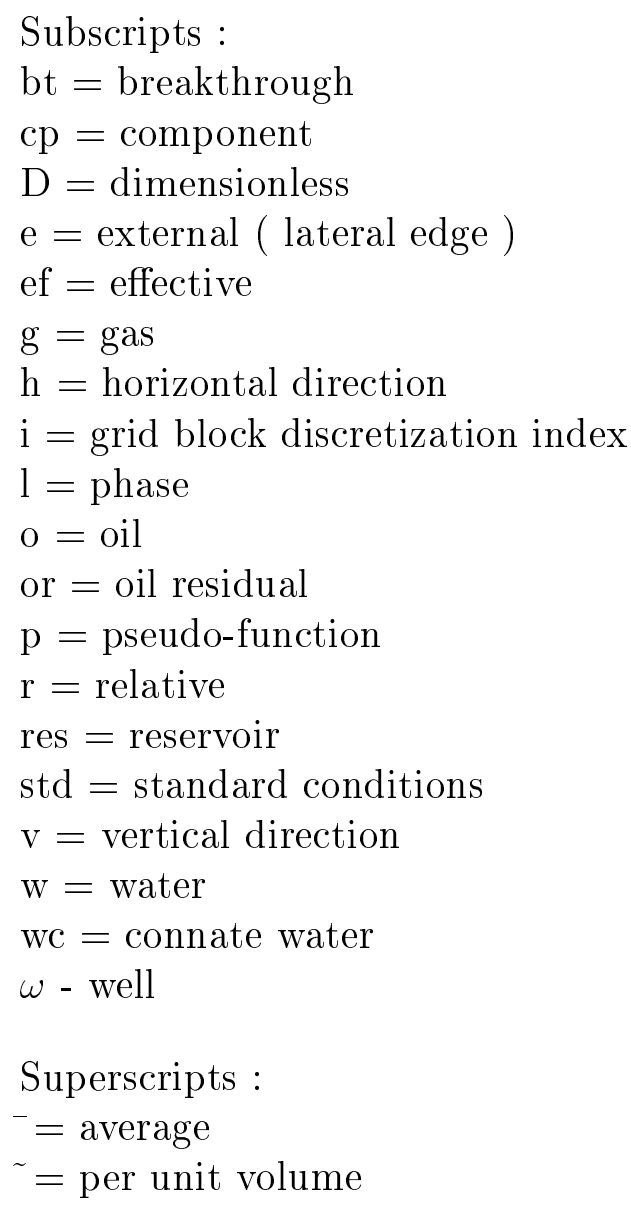




\section{References}

1. Horne, R. N.: Notes for Applied Mathematics in Reservoir Engineering, Stanford University, 1994.

2. Tiefenthal, S. A.: "Supercritical Production from Horizontal Wells in Oil-Rim Reservoirs," SPERE, November 1994, 272-277. 